\title{
Using Anodization to Oxidize Ultrathin Aluminum Film for High- $k$ Gate Dielectric Application
}

\section{Yen-Po Lin and Jenn-Gwo Hwu}

Department of Electrical Engineering, Graduate Institute of Electronics Engineering, National Taiwan University, Taipei, Taiwan

\begin{abstract}
Very low cost room-temperature process to fabricate ultrathin $\mathrm{Al}_{2} \mathrm{O}_{3}$ high-k gate dielectrics with equivalent oxide thickness of 10 to $35 \AA$ was studied in this work. Anodic oxidation (anodization) in deionized water followed with rapid thermal annealing was used to oxidize ultrathin aluminum film. Unlike thermal oxidation, anodic $\mathrm{Al}_{2} \mathrm{O}_{3}$ possesses a speciality of self-limited oxide thickness. This work also demonstrated that the anodic $\mathrm{Al}_{2} \mathrm{O}_{3}$ exhibits gate dielectric quality characteristics, including low gate leakage current, low interface states, and low bulk trap density. The dielectric constant of anodic $\mathrm{Al}_{2} \mathrm{O}_{3}$ is estimated to be 9.7. In addition, the gate current density, $\mathrm{Jg}$, is almost independent of the measurement temperature, revealing a low trap density and high thermal stability. These good insulator characteristics are believed to be related to the leakage path self-readjustment nature under electric field influence in liquid during anodization.

(C) 2003 The Electrochemical Society. [DOI: 10.1149/1.1577545] All rights reserved.
\end{abstract}

Manuscript submitted August 13, 2002; revised manuscript received January 13, 2003. Available electronically May 16, 2003

For the silicon complementary metal oxide semiconductor (CMOS) scaling beyond $100 \mathrm{~nm}$ technology node, the exponential increase in tunneling current with decreasing film thickness becomes an important factor for limiting the reduction of oxide thickness. This thickness-scaling limit is considered to be $12 \AA$ due to high gate leakage and degraded transistor performance. ${ }^{1}$ Therefore, to keep device area small and prevent high leakage current while maintaining the same gate capacitance, a thicker gate dielectric with $k$ $>3.9$ is necessary for the advanced technology node. Several high- $k$ materials including $\mathrm{Al}_{2} \mathrm{O}_{3}, \mathrm{Si}_{3} \mathrm{~N}_{4}, \mathrm{ZrO}_{2}$ and $\mathrm{HfO}_{2}$ had been proposed to provide a substantial thicker dielectric film for reduced leakage current and improved gate capacitance..$^{2-4}$

However, for most high- $k$ materials, higher dielectric constant comes at the expense of narrower bandgap, which can itself result in leakage current. It is noted that due to directly abutting the transistor channel, high- $k$ gate dielectrics must be thermally stable during subsequent high temperature process if they are incorporated into a conventional CMOS process flow. Among the existing high- $k$ materials, $\mathrm{Al}_{2} \mathrm{O}_{3}$ is a strong candidate, since it has a bandgap of $\sim 9 \mathrm{eV}$ similar to $\mathrm{SiO}_{2},{ }^{5}$ and is an inert high temperature material which is expected to withstand silicon processing conditions. Many methods had been proposed to prepare the $\mathrm{Al}_{2} \mathrm{O}_{3}$ films, such as thermal oxidization under $\mathrm{O}_{2}$ ambient, atomic layer deposition (ALD) and sputter deposition-based techniques. ${ }^{2,5-7}$ Generally, a substantial interfacial silicon oxide layer was observed during high temperature procedure due to the rapid oxygen diffusion through thin $\mathrm{Al}_{2} \mathrm{O}_{3}{ }^{8}$ Although it is well known that $\mathrm{SiO}_{2}$ has an excellent interface quality with $\mathrm{Si}$, an uncontrolled amount of $\mathrm{SiO}_{2}$ formation will decrease the capacitance of the dielectric, which can be detrimental to the higher $k$ value. We believe that if an ultrathin $\mathrm{SiO}_{2}$ layer could be formed between $\mathrm{Al}_{2} \mathrm{O}_{3}$ and $\mathrm{Si}$ during process, the interface quality could be comparable to that of $\mathrm{SiO}_{2} / \mathrm{Si}$ or the interface between $\mathrm{SiO}_{2}$-based gate dielectric and $\mathrm{Si}$. This would avoid the need of additional interface engineering, so the higher dielectric constant value could be fully utilized.

In this work, we present a liquid phase oxidation method to oxidize the $\mathrm{Al}$ film. Room temperature anodization in deionized (DI) water is used to oxidize Al then rapid thermal annealing (RTA) follows for the preparation of the high- $k$ gate dielectric. According to the existing literature, ${ }^{9,10}$ anodic $\mathrm{SiO}_{2}$ exhibits excellent electrical characteristics such as lower leakage current and higher breakdown field endurance than conventional thermal $\mathrm{SiO}_{2}$. With the additional merits of low thermal budget and low cost, anodic oxidation is attractive in high-density integrated circuit application. Also, an ap-

z E-mail: hwu@cc.ee.ntu.edu.tw propriate annealing is efficient in controlling the electrical properties of anodic oxide. ${ }^{9}$ The results, show that the anodic $\mathrm{Al}_{2} \mathrm{O}_{3}$ shows gate dielectric quality characteristics of low leakage current, low interface states, and low bulk trap density. This is of interest for the high- $k$ gate dielectrics preparation by using the technique in this work.

\section{Experimental}

Prior to anodization, 3 in. p-type $\mathrm{Si}$ wafers were treated with standard RCA cleaning. A final HF dip procedure was adopted to remove the native oxide. $1 \%$-Si-doped $\mathrm{Al}$ was then evaporated on the Si wafer with different thicknesses from 7 to $43 \AA$.

In the following anodization procedure, wafer with $\mathrm{Al}$ film act as an anode electrode. Constant electrolyzing field of $10 \mathrm{~V} / \mathrm{cm}$ was applied from 5 to 30 min separately at room temperature by using DI water as electrolyte. After anodization, postanodization annealing (PAA) with RTA system was treated in $\mathrm{N}_{2}$ ambient from 500 to $900^{\circ} \mathrm{C}$. All the samples were examined by high resolution Auger electron spectrometry (AES; Physical Electronics, AES PHI670xi), X-ray photoelectron spectroscopy (XPS; Physical Electronics, ESCA PHI 1600), and ellipsometry to characterize the depth profile, near-surface region bonding condition, and the optical (physical) thickness, respectively.

After the aluminum oxide dielectric was formed, standard lithography and etching processes were utilized to fabricate MOS capacitor structure devices with $\mathrm{Al}$ metal gate area of $150 \times 150 \mu \mathrm{m}$. In addition, conventional $\mathrm{SiO}_{2}$ dielectrics prepared by rapid thermal oxidation (RTO) system were also fabricated at the same time for comparison. After capacitor devices were implemented, capacitancevoltage $(\mathrm{C}-\mathrm{V})$ and current density-voltage $(\mathrm{J}-\mathrm{V})$ measurements were used to analyze the electrical characteristics. Also, the equivalent oxide thickness (EOT) was obtained from two high-frequency (100 $\mathrm{KHz}$ and $1 \mathrm{MHz}) \mathrm{C}-\mathrm{V}$ measurements in strong accumulation region using a dielectric constant of 3.9 , considering the series resistance and quantum mechanical effect. ${ }^{11,12}$

\section{Results and Discussion}

Depth profile and near-surface region bonding analysis.-After $43 \AA$ aluminum was anodized under a constant field of $10 \mathrm{~V} / \mathrm{cm}$ for 20 min, the depth profile of anodic $\mathrm{Al}_{2} \mathrm{O}_{3}$ before and after $900^{\circ} \mathrm{C}$ PAA was inspected by AES with a very low sputter rate as shown in Fig. 1. It is observed that the anodization could oxidize the $\mathrm{Al}$ into a very uniform $\mathrm{Al}_{2} \mathrm{O}_{3}$ at room temperature. After PAA, the $\mathrm{Al}$ distribution was not significantly different from that before annealing, which reveals that the anodic $\mathrm{Al}_{2} \mathrm{O}_{3}$ is quite thermal stable under $900^{\circ} \mathrm{C}$ annealing ambient. Also, a very thin $\mathrm{SiO}_{2}$ layer, which is estimated as thinner than $5 \AA$, was observed in the $\mathrm{Al}_{2} \mathrm{O}_{3} / \mathrm{Si}$ inter- 


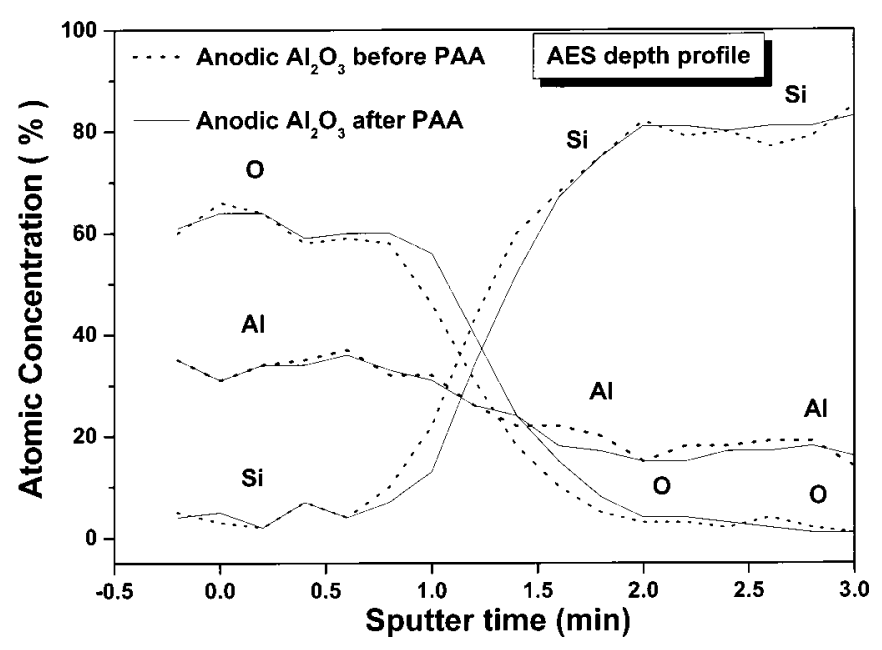

Figure 1. AES depth profile of $\mathrm{O}, \mathrm{Al}$, and $\mathrm{Si}$ relative atomic concentration for one anodic $\mathrm{Al}_{2} \mathrm{O}_{3}$ sample before and after PAA.

face after $\mathrm{N}_{2}$ annealing. We believe that hydrated alumina $\left(\mathrm{Al}_{2} \mathrm{O}_{3} \cdot \mathrm{H}_{2} \mathrm{O}\right)$ and $\mathrm{Al}(\mathrm{OH})_{3}$ could coexist in the anodic $\mathrm{Al}_{2} \mathrm{O}_{3}$ after anodization. While PAA was treated to evolve the hydrogen from the anodic $\mathrm{Al}_{2} \mathrm{O}_{3}$, the excess oxygen interacted with the bulk silicon at the same time. Thus, an ultrathin $\mathrm{SiO}_{2}$ interfacial layer could be self-formed between $\mathrm{Al}_{2} \mathrm{O}_{3}$ and $\mathrm{Si}$ during high temperature annealing. This interfacial $\mathrm{SiO}_{2}$ is helpful to obtain a satisfactory interface for device application.

The near-surface region bonding condition was characterized by ex situ XPS using monochromatic $\mathrm{Mg} K \alpha$ radiation. Figure 2a and $\mathrm{b}$ show the Al 2p XPS spectra of original evaporated $\mathrm{Al}$ and anodic $\mathrm{Al}_{2} \mathrm{O}_{3}$, respectively. In Fig. 2a, it is seen that the $\mathrm{Al} 2 \mathrm{p}$ bondings of metallic-state $\mathrm{Al}\left(\mathrm{Al}^{0}\right)$ and $\mathrm{Al}_{2} \mathrm{O}_{3}\left(\mathrm{Al}^{3+}\right)$ coexist on the evaporated Al surface, which indicates the easily formed aluminum native oxide. After 10 min anodization, no signal from metallic $\mathrm{Al}$ is observed in Fig. 2b. The binding energy is $75.9 \mathrm{eV}$, which implies that the metallic $\mathrm{Al}$ was almost converted into stoichiometric $\mathrm{Al}_{2} \mathrm{O}_{3}$ after anodization. ${ }^{13}$

In Fig. 3, the evolution of Si $2 p$ spectra varied with the anodization time was shown to observe the interfacial transformation. For the silicon oxide, four different bonding configurations were admit-

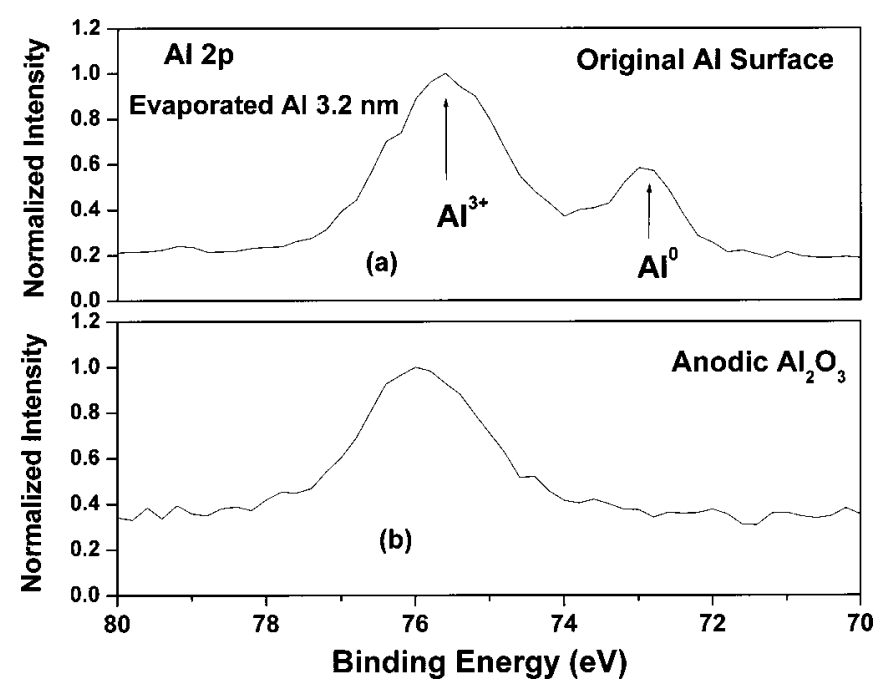

Figure 2. XPS Al 2p spectra for Al films (a) before and (b) after $10 \mathrm{~min}$ anodization. $\mathrm{Al}$ was almost converted into $\mathrm{Al}_{2} \mathrm{O}_{3}$ after anodization.

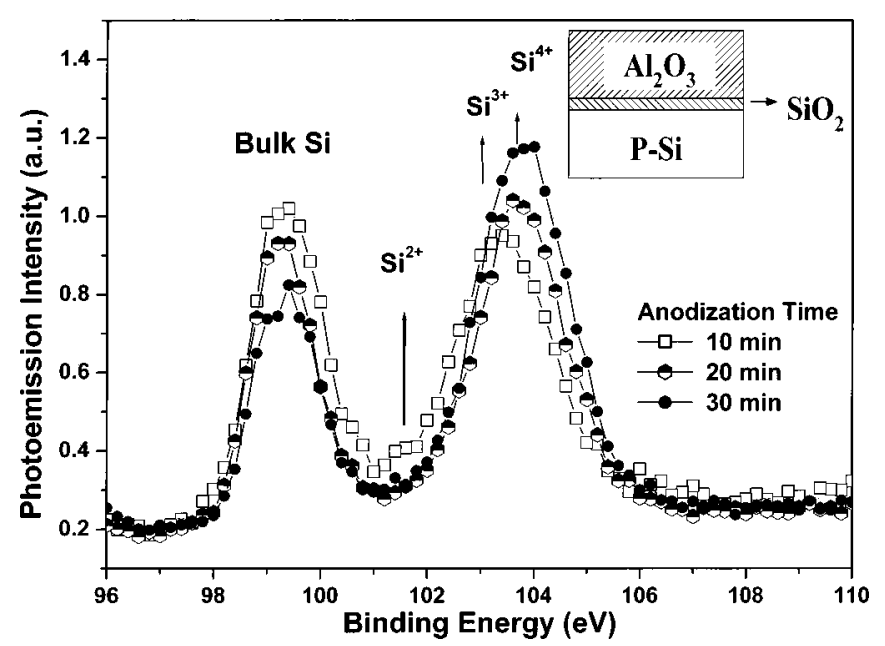

Figure 3. Evolution of XPS Si 2p spectra for the evaporated Al films anodized after 10, 20, and $30 \mathrm{~min}$. The underneath $\mathrm{Si}$ signals demonstrate the relative $\mathrm{SiO}_{2}$ intensity increases with the anodization time. The inset depicts the structure after anodization.

ted, i.e., $\mathrm{Si}^{1+}, \mathrm{Si}^{2+}, \mathrm{Si}^{3+}$, and $\mathrm{Si}^{4+}$, which have distinguishable energy shifts to the bulk silicon, i.e., $1.0,1.8,2.7$, and $3.5 \mathrm{eV}$, respectively. ${ }^{14}$ After 10 min anodization, the $\mathrm{Si}^{2+}$ spectrum with a peak around $101.6 \mathrm{eV}$ can be attributed to the mixture of $\mathrm{Si}$ and $\mathrm{Al}_{2} \mathrm{O}_{3}$ at interface. We may suppose this mixture layer is composed of silicon oxide and silicon suboxide. While the anodization time increased, we can see the $\mathrm{Si}^{2+}$ signal disappeared and transferred to $\mathrm{Si}^{4+}\left(\mathrm{SiO}_{2}\right)$. From the AES and XPS analyses, we can see that this interfacial $\mathrm{SiO}_{2}$ is grown during anodization and annealing procedures. Therefore, controlling the anodization and annealing processes, would eliminate the need of additional interface engineering. The schematic structure of anodic $\mathrm{Al}_{2} \mathrm{O}_{3}$ is shown in the inset of Fig. 3.

Behavior of $\mathrm{Al}_{2} \mathrm{O}_{3}$ anodization.-From the recent reports, ${ }^{2,8,13}$ the bottom silicon oxide beneath thin $\mathrm{Al}_{2} \mathrm{O}_{3}$ could be easily formed during high temperature oxidation process. Any annealing treatment with excess oxygen present will lead to rapid oxygen diffusion through the oxides, and therefore resulting in an $\mathrm{SiO}_{2}$ or $\mathrm{SiO}_{2}$-containing interface. The $\mathrm{SiO}_{2} / \mathrm{Si}$ interface is well known to possess high quality characteristics, i.e., low interface state density $\sim 10^{10} \mathrm{~cm}^{-2} \mathrm{eV}^{-1}$, and low tap density. Nevertheless, a thick interfacial $\mathrm{SiO}_{2}$ can seriously limit the EOT scaling under $12 \AA$. Therefore, it is worth studying how to preserve the critical high quality nature of the $\mathrm{SiO}_{2}$ interface without sacrificing the higher- $k$ merit.

In Fig. 4, EOT of anodic $\mathrm{Al}_{2} \mathrm{O}_{3}$ vs. anodization time is shown. It is observed that the $\mathrm{Al}$ film can be rapidly oxidized into $\mathrm{Al}_{2} \mathrm{O}_{3}$ and subsequently self-limited to a saturated oxide thickness, especially when the evaporated $\mathrm{Al}$ thickness is thicker than $30 \AA$. We can attribute this result to the electrical field limitation. After Al had been converted into $\mathrm{Al}_{2} \mathrm{O}_{3}$, most voltage between electrodes would drop over $\mathrm{Al}_{2} \mathrm{O}_{3}$ due to its higher resistance, which could lead rapidly to a reduced oxidation rate. This is verified by extracting the resistances of DI water and $\mathrm{Al}_{2} \mathrm{O}_{3}$ layer from our anodization system and $\mathrm{C}-\mathrm{V}$ measurement. The resistance of DI water is calculated to be $\sim 10^{4} \Omega$ under $10 \mathrm{~V} / \mathrm{cm}$ constant field anodization, and the $\mathrm{Al}_{2} \mathrm{O}_{3}(40 \AA)$ layer extracted from two frequency $\mathrm{C}-\mathrm{V}$ measurements is about $\sim 10^{6} \Omega{ }^{11}$ Based on this characteristic, it may be possible, if an appropriate anodization field is selected, to precisely control the ultimate interfacial oxide thickness without sacrificing the higher- $k$ value.

In order to find out the dielectric constant of anodic $\mathrm{Al}_{2} \mathrm{O}_{3}$, the equations shown below are utilized to determine the $k$ value 


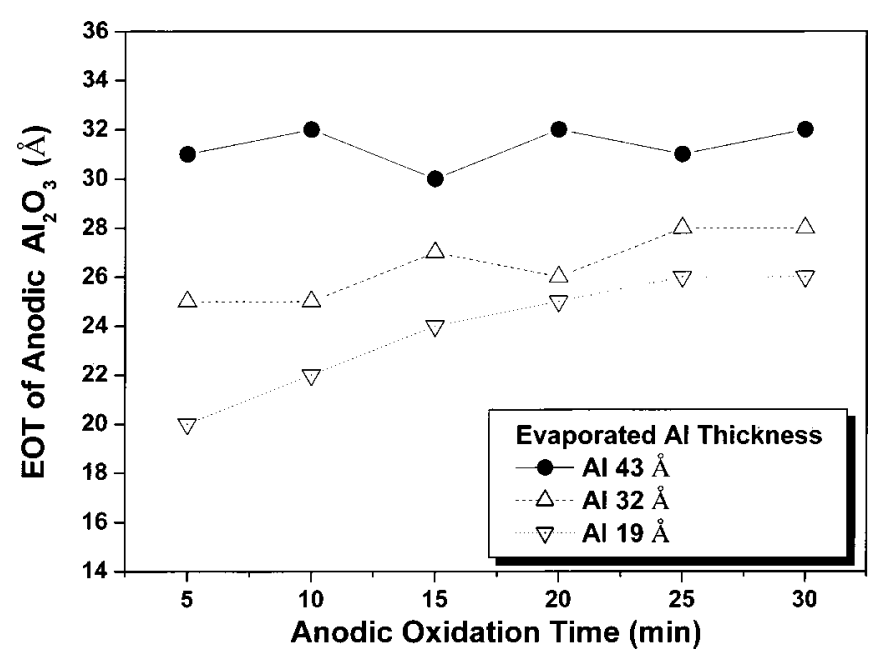

Figure 4. EOT of anodic $\mathrm{Al}_{2} \mathrm{O}_{3}$ vs. anodization time. This chart shows a self-limited oxide thickness characteristic during anodization.

$$
\varepsilon_{\mathrm{ox}} / \mathrm{EOT}=\varepsilon_{\mathrm{Al}_{2} \mathrm{O}_{3}} / T_{\mathrm{Al}_{2} \mathrm{O}_{3}}
$$

and

$$
\Delta \mathrm{EOT} / \Delta T_{\mathrm{Al}_{2} \mathrm{O}_{3}}=\varepsilon_{\mathrm{ox}} / \varepsilon_{\mathrm{Al}_{2} \mathrm{O}_{3}}
$$

where EOT is the equivalent oxide thickness with the consideration of quantum mechanical effect, $T_{\mathrm{Al}_{2} \mathrm{O}_{3}}$ is the thickness of $\mathrm{Al}_{2} \mathrm{O}_{3}$ that is obtained from ellipsometer with $n=1.66, \varepsilon_{\mathrm{ox}}=3.9 \varepsilon_{\mathrm{o}}$ is the dielectric constant of $\mathrm{SiO}_{2}$, and $\varepsilon_{\mathrm{Al}_{2} \mathrm{O}_{3}}$ is the dielectric constant of $\mathrm{Al}_{2} \mathrm{O}_{3}$.

In Fig. 5, EOT vs. $\mathrm{Al}_{2} \mathrm{O}_{3}$ optical thickness is plotted to determine the dielectric constant of anodic $\mathrm{Al}_{2} \mathrm{O}_{3}$. From the slope, one obtains a dielectric constant of anodic $\mathrm{Al}_{2} \mathrm{O}_{3}$ of $\varepsilon_{\mathrm{Al}_{2} \mathrm{O}_{3}} \sim 9.7 \varepsilon_{\mathrm{o}}$.

Electrical characteristics of anodic $\mathrm{Al}_{2} \mathrm{O}_{3}$. - Figure $6 \mathrm{a}$ and $\mathrm{b}$ shows the $\mathrm{C}-\mathrm{V}$ curves of anodic $\mathrm{Al}_{2} \mathrm{O}_{3}$ before and after $\mathrm{N}_{2}$ RTA annealing, i.e., PAA, respectively. In Fig. 6a, the $\mathrm{C}-\mathrm{V}$ hysteresis loop is apparent $\left(\Delta V_{\mathrm{fb}} \sim 0.5 \mathrm{~V}\right)$. From the inserted figure, one can also observe the $\mathrm{C}-\mathrm{V}$ curve appears a stretched out phenomenon, which

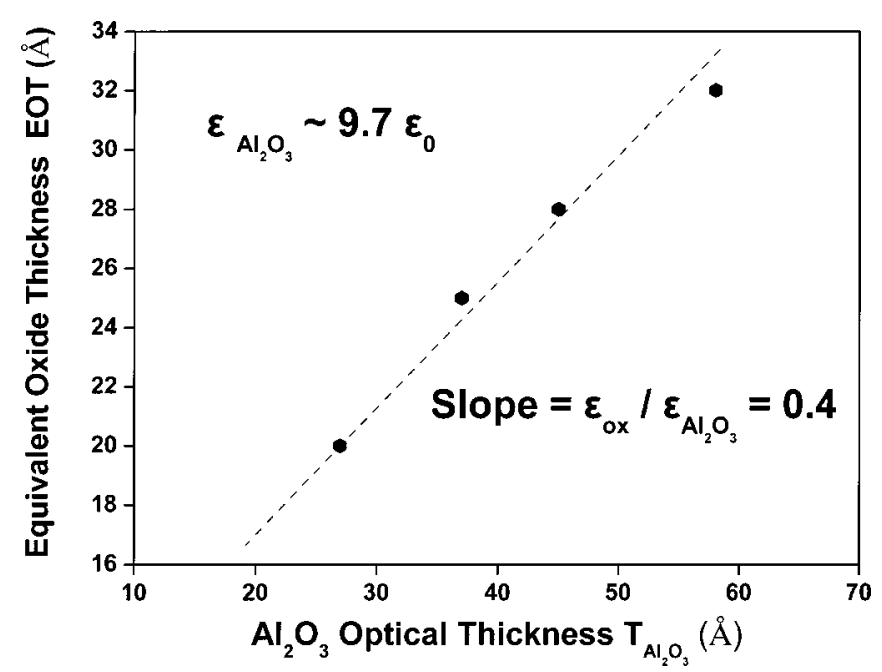

Figure 5. EOT vs. optical thickness of $\mathrm{Al}_{2} \mathrm{O}_{3}$. The slope yield a dielectric constant of $k \sim 9.7$.

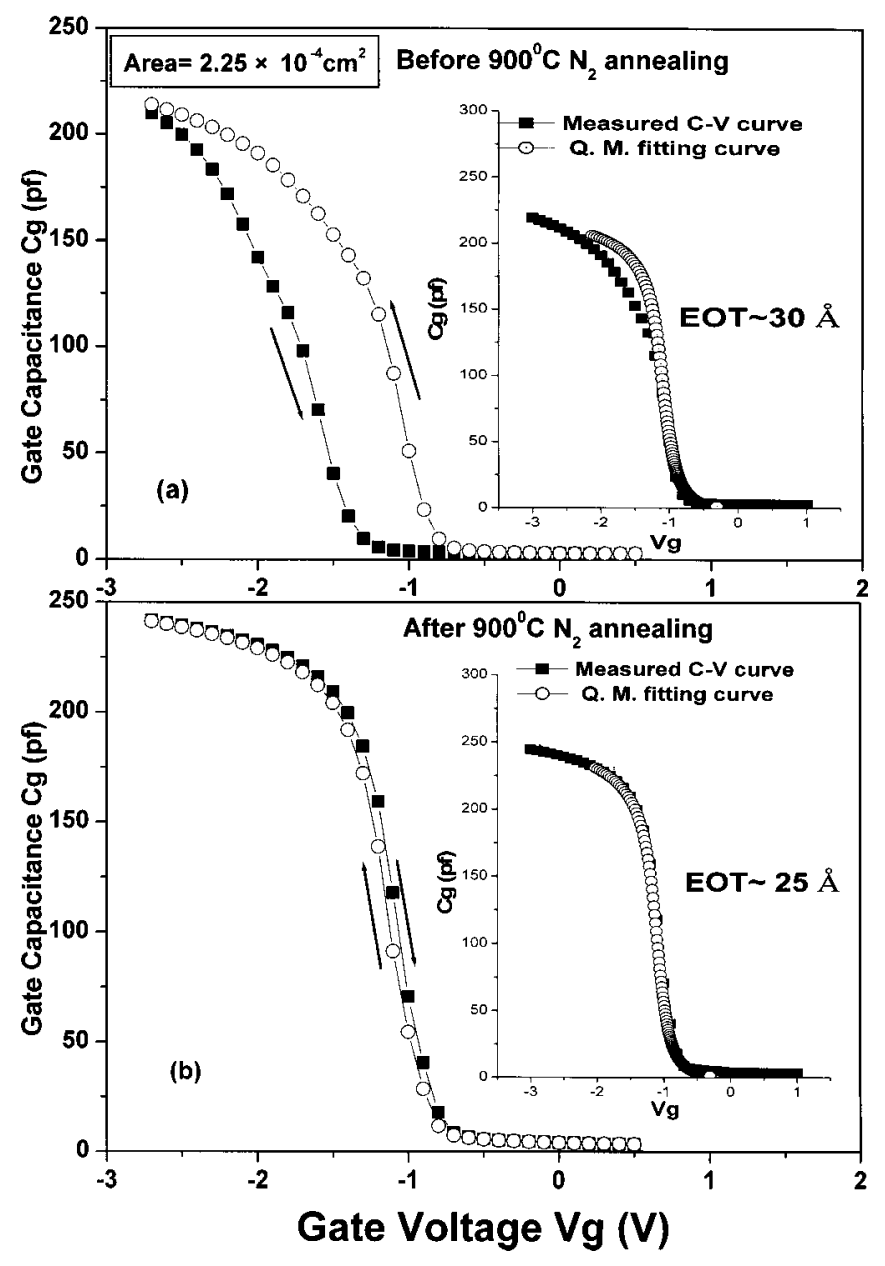

Figure 6. $1 \mathrm{MHz} \mathrm{C}-\mathrm{V}$ curves for anodic $\mathrm{Al}_{2} \mathrm{O}_{3}$ (a) before and (b) after $900^{\circ} \mathrm{C} \mathrm{N}_{2}$ RTA. The simulated C-V curves are shown in the inserted figures for comparison. In (a), the C-V curve shows apparent hysteresis and stretch out phenomenon.

reveals noticeable trapped charges in the dielectric before annealing. ${ }^{15}$ After the anodic $\mathrm{Al}_{2} \mathrm{O}_{3}$ films were treated with $900^{\circ} \mathrm{C}$ $\mathrm{N}_{2}$ RTA annealing, the hysteresis loop almost disappears, as shown in Fig. 6b. Also, the C-V curve fits the theoretical $25 \AA$ oxide $\mathrm{C}-\mathrm{V}$ curve very well, ${ }^{12}$ indicating an excellent gate dielectric quality film. In addition, the capacitance is obviously increased after annealing, which implies a denser dielectric formed after PAA.

It is known that the trapping of positive charges under a constant current stress will result in a reduction in gate voltage, while that of negative charges will result in an increase in gate voltage. Figure 7 shows the variation of $V \mathrm{~g}$ under a $-1 \mathrm{~A} / \mathrm{cm}^{2}$ constant current stress. It shows a very different trapping mechanism. The anodic $\mathrm{Al}_{2} \mathrm{O}_{3}$ film without annealing contains a great amount of hole and electron traps with respect to the annealed one, the latter exhibits fewer net electron traps. High frequency $\mathrm{C}-\mathrm{V}$ curves with $100 \mathrm{KHz}$ and 1 $\mathrm{MHz}$ measurements are shown in the inset of Fig. 7. The capacitance variation in the accumulation region denotes the series resistance effect, which exists in the device structure and the measurement system. ${ }^{11}$ Furthermore, we can observe the depletion and inversion region curves are almost independent of the frequency. This implies that the interface state density is very low, because a higher interface state density makes the $\mathrm{C}-\mathrm{V}$ curve response as frequency going down. Many works have shown that the $\mathrm{OH}^{-}$related chemical species involved in the $\mathrm{SiO}_{2}$ could act as trapping centers and degrade the device performance due to high trap-assisted current and poor interface quality. ${ }^{16,17}$ This phenomenon is also found 


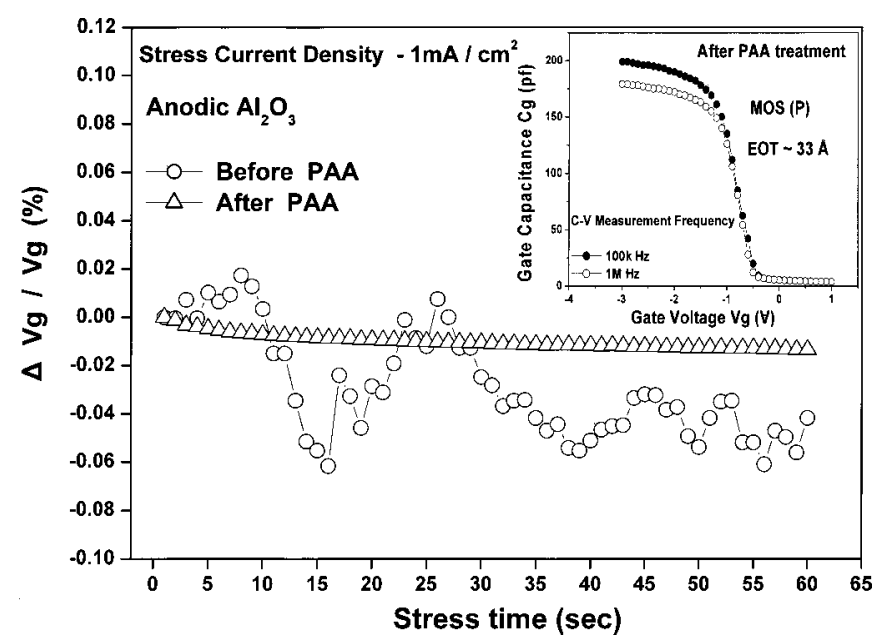

Figure 7. Variations of $\Delta V \mathrm{~g} /|V \mathrm{~g}|$ vs. stress time under a constant current density of $-1 \mathrm{~mA} / \mathrm{cm}^{2}$ for one sample before and after PAA. Two frequency $\mathrm{C}-\mathrm{V}$ curves with $100 \mathrm{KHz}$ and $1 \mathrm{MHz}$ are shown in the inset.

in as-anodized $\mathrm{Al}_{2} \mathrm{O}_{3}$. High temperature PAA is necessary after anodization because it can effectively evolve the hydrogen from the anodic $\mathrm{Al}_{2} \mathrm{O}_{3}$, suppress the trap center generation, and make it a denser dielectric.

From the previous discussion, anodic $\mathrm{Al}_{2} \mathrm{O}_{3}$ without PAA showed a poor interface quality, i.e., too many interface states and trap densities. PAA was carried out to improve the interface quality. $\mathrm{J}-\mathrm{V}$ plots of original native oxide and anodic $\mathrm{Al}_{2} \mathrm{O}_{3}$ with and without PAA treatment are shown in Fig. 8. The native $\mathrm{Al}_{2} \mathrm{O}_{3}$ film shows a very poor insulator characteristic. After anodization, the J-V curve presents a two orders reduction in current level than native oxide at $-2 \mathrm{~V}$, but it is still very leaky. However after the subsequent PAA treatment, oxide resistance shows a drastic improvement, the current level was reduced for four orders of magnitude further. It is suggested that the oxidant, i.e., $\mathrm{OH}^{-}$, could drift through the anodic $\mathrm{Al}_{2} \mathrm{O}_{3}$ and then react with underlying metallic $\mathrm{Al}$ by breaking the $\mathrm{Al}-\mathrm{Al}$ or Al-Si bonds during anodization. ${ }^{13}$ The drift paths could be consequently formed after anodization. After PAA treatment, the drift paths could be repaired in a high temperature ambient. From previous discussions, we can notice that PAA procedure plays an

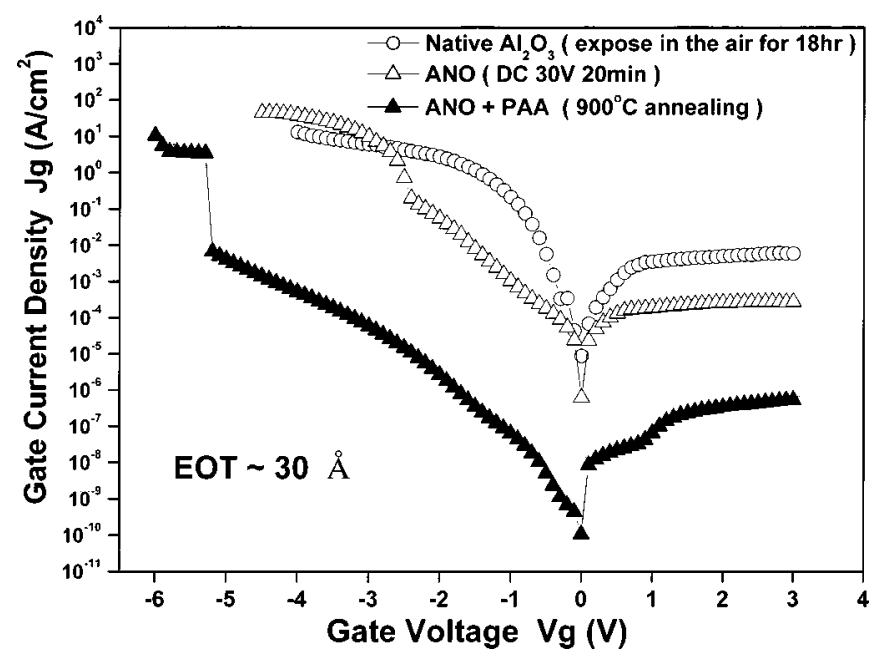

Figure 8. Evolution of $\mathrm{J}-\mathrm{V}$ plots of samples before anodization (native $\mathrm{Al}_{2} \mathrm{O}_{3}$ ), after anodization (ANO), and then after annealing (ANO+PAA). indispensable role to strengthen the anodic $\mathrm{Al}_{2} \mathrm{O}_{3}$ bonding network and make it a dense insulator film.

Except the gate leakage current, interface quality is an important issue of high- $k$ gate dielectric to substitute $\mathrm{SiO}_{2}$. In Fig. 9, high frequency $\mathrm{C}-\mathrm{V}$ curves with superimposed ac signals of $1 \mathrm{MHz}, 100$ $\mathrm{KHz}, 10 \mathrm{KHz}$, and $1 \mathrm{KHz}$ are employed to analyze the response of interface states. The raised capacitance with decreasing frequency in depletion region can attribute to the response of interface states. As can be seen, the stretch-out phenomenon is obviously reduced with the increased PAA temperature. (Fig. 9a-d). When annealing temperature was raised to $700^{\circ} \mathrm{C}$, the $\mathrm{C}-\mathrm{V}$ stretch-out phenomenon is much improved as shown in Fig. 9c. We believe that the $\mathrm{OH}^{-}$related trap can be removed after PAA and the interfacial $\mathrm{SiO}_{2}$ grow at the same time when temperature was raised to $700^{\circ} \mathrm{C}$. However, the interface states induced $\mathrm{C}-\mathrm{V}$ distortion in depletion region is still apparent. When the PAA temperature was raised to $900^{\circ} \mathrm{C}$, the interface states response shows a very slight dependence on frequency, revealing a low interface states density. From the discussion, we can see a higher temperature annealing is critical to the interface quality of anodic $\mathrm{Al}_{2} \mathrm{O}_{3}$.

Gate leakage current density of anodic $\mathrm{Al}_{2} \mathrm{O}_{3}$ and $\mathrm{RTO} \mathrm{SiO}_{2}$ as a function of EOT ranging from 10 to $35 \AA$ (gate bias at $V \mathrm{~g}-V_{\mathrm{fb}}$ $=-1 \mathrm{~V}$ ) is shown in Fig. 10. The anodic $\mathrm{Al}_{2} \mathrm{O}_{3}$ shows about 1.5 orders reduced leakage current with respect to $\mathrm{SiO}_{2}$ under the same EOT. Besides, J-V plots of anodic $\mathrm{Al}_{2} \mathrm{O}_{3}$ and $\mathrm{SiO}_{2}$ with EOTs of 20 and $25 \AA$ are shown in the inset of Fig. 10. The anodic $\mathrm{Al}_{2} \mathrm{O}_{3}$ with an EOT of about $10 \AA$ is also shown for comparison. The anodic $\mathrm{Al}_{2} \mathrm{O}_{3}$ exhibits a lower leakage current and higher breakdown voltage than conventional $\mathrm{SiO}_{2}$ that was mainly attributed to the thicker physical thickness of $\mathrm{Al}_{2} \mathrm{O}_{3}$ under the same EOT. This result reveals the room temperature anodization process followed by PAA could be utilized to obtain a desirable gate quality $\mathrm{Al}_{2} \mathrm{O}_{3}$ dielectric.

Figure 11 shows the comparison of time-zero-dielectricbreakdown (TZDB) characteristics of $\mathrm{SiO}_{2}$ and anodic $\mathrm{Al}_{2} \mathrm{O}_{3}$ samples with an EOT of $25 \AA$. Anodic $\mathrm{Al}_{2} \mathrm{O}_{3}$ samples can suffer $\sim 3$ $\mathrm{MV} / \mathrm{cm}$ larger field to breakdown than the $\mathrm{SiO}_{2}$ samples. In addition, it presents a more uniform distribution than thermally grown $\mathrm{SiO}_{2}$. It is known that fewer pinholes can induce a better insulator characteristic and higher breakdown field. The interfacial oxide grown during anodization and PAA exhibits a more uniform electrical characteristic due to the self-readjustment nature of the current leakage path and high temperature repairing of unsatisfied bonding. A more uniform oxide exhibits less local thinning and therefore a higher breakdown field.

Figure 12 shows the characteristics of temperature-dependent reliability of J-V curves measured from 25 to $100^{\circ} \mathrm{C}$. When the device was positively biased at inversion region, i.e., substrate injection region, the saturated leakage current level varied with the measurement temperature. From recent research, ${ }^{18}$ the main composition of saturated current was generated from the penetration of minority carriers via the interface states. While the minority carriers were not sufficient for supporting the tunneling current, the current could be saturated in a specific level. The specific saturated level is strongly temperature dependent since the intrinsic carrier concentration is proportional to the substrate temperature. ${ }^{19}$ Therefore, the current level increased with the measurement temperature.

In the other aspect, when the device was negatively biased at accumulation region, i.e., gate injection region, the conduction characteristics had a very weak temperature dependency. Unlike FowlerNordheim (F-N) tunneling in $\mathrm{SiO}_{2}$, the dominant conduction mechanism in thermally oxidized $\mathrm{Al}_{2} \mathrm{O}_{3}$ was reported to be FrankelPoole (F-P) emission, ${ }^{2}$ in which the conduction mechanism is based on the capture and emission of carriers from traps in the bulk. In F-P conduction, the trap-assisted tunneling current is strongly dependent on the measurement temperature. ${ }^{2,20}$ However, in this work, the anodic $\mathrm{Al}_{2} \mathrm{O}_{3}$ shows that the current is almost independent of the 

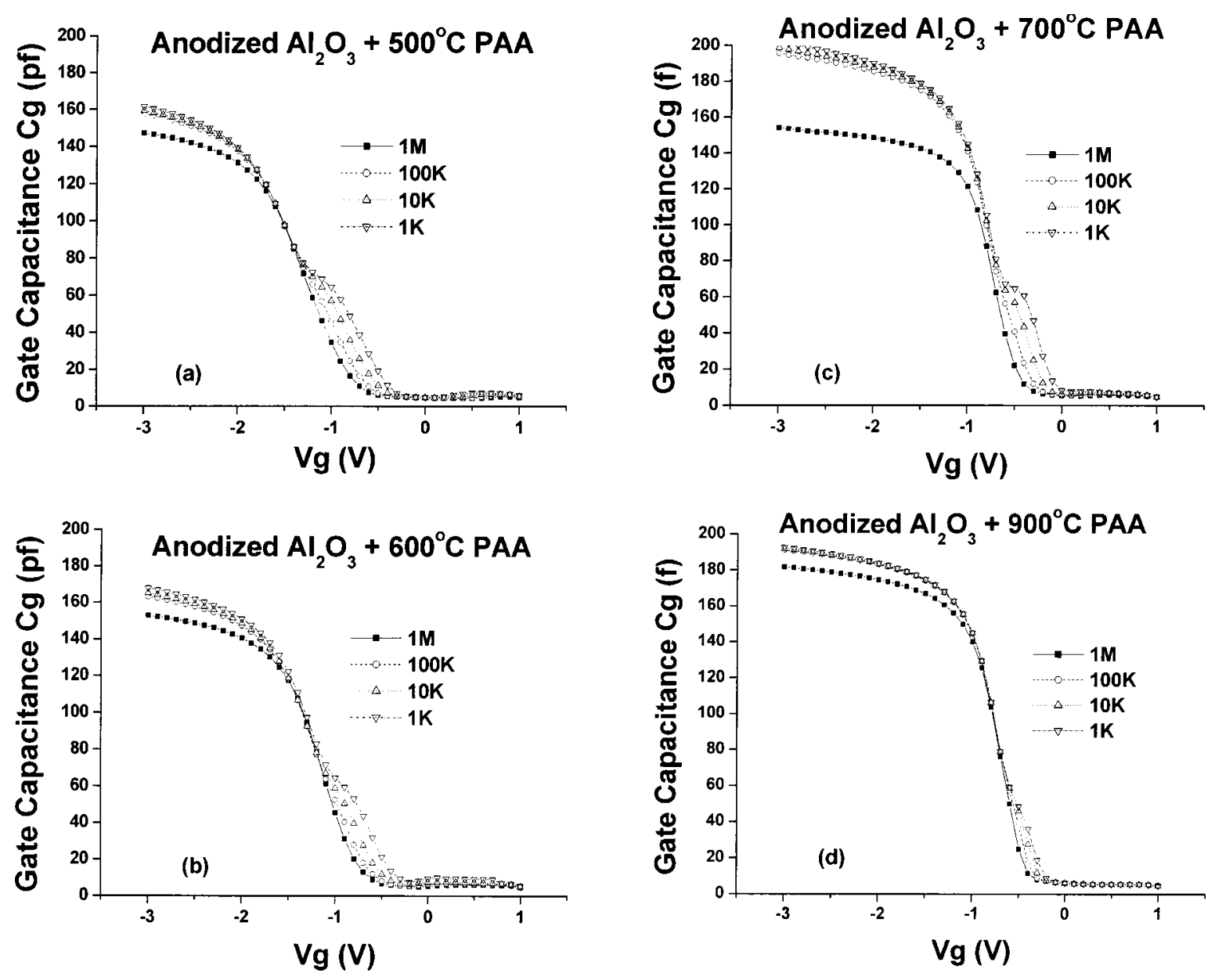

Figure 9. $1 \mathrm{M}, 100 \mathrm{k}, 10 \mathrm{k}, 1 \mathrm{k} \mathrm{Hz}$ high frequency $\mathrm{C}-\mathrm{V}$ curves of anodic $\mathrm{Al}_{2} \mathrm{O}_{3}$ samples after (a) $500^{\circ} \mathrm{C}$, (b) $600^{\circ} \mathrm{C}$, (c) $700^{\circ} \mathrm{C}$, (d) $900^{\circ} \mathrm{C}$ PAA. Bulk traps and interface states densities decrease with annealing temperature.

measurement temperature as shown in Fig. 13. In addition, by observing the inset in Fig. 13, the $\mathrm{J}-\mathrm{V}$ curve of anodic $\mathrm{Al}_{2} \mathrm{O}_{3}$ is well fitted by the F-N plot in high field region. It is believed that the lack of traps in the anodic $\mathrm{Al}_{2} \mathrm{O}_{3}$ could be responsible for the tendency of F-N like tunneling of the $\mathrm{Al}_{2} \mathrm{O}_{3}$ dielectric in this work.

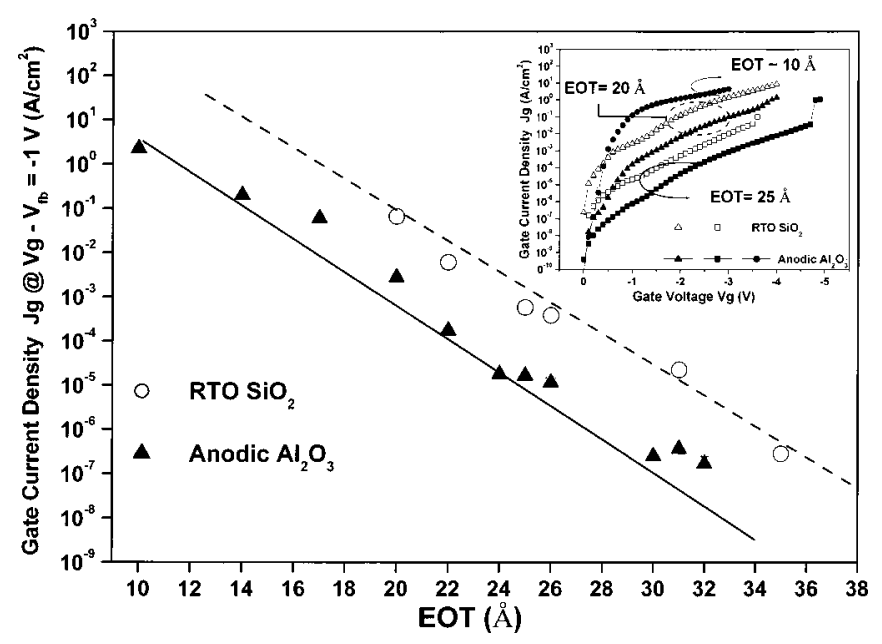

Figure 10. Gate leakage current densities vs. EOT of anodic $\mathrm{Al}_{2} \mathrm{O}_{3}$ and conventional $\mathrm{SiO}_{2}$ samples with a gate bias of $V \mathrm{~g}-V_{\mathrm{fb}}=-1 \mathrm{~V}$. Also, J-V plots of samples with EOTs of 10, 20, and $25 \AA$ are shown in the inset.

\section{Conclusion}

Ultrathin $\mathrm{Al}_{2} \mathrm{O}_{3}$ high- $k$ gate dielectric preparation by DI water anodization was demonstrated in this work. Unlike thermal oxidation, it was found that anodic $\mathrm{Al}_{2} \mathrm{O}_{3}$ has the merits of a $\mathrm{Si}-\mathrm{SiO}_{2}$ interface in Fig. 3, low leakage current, and low trap density char-

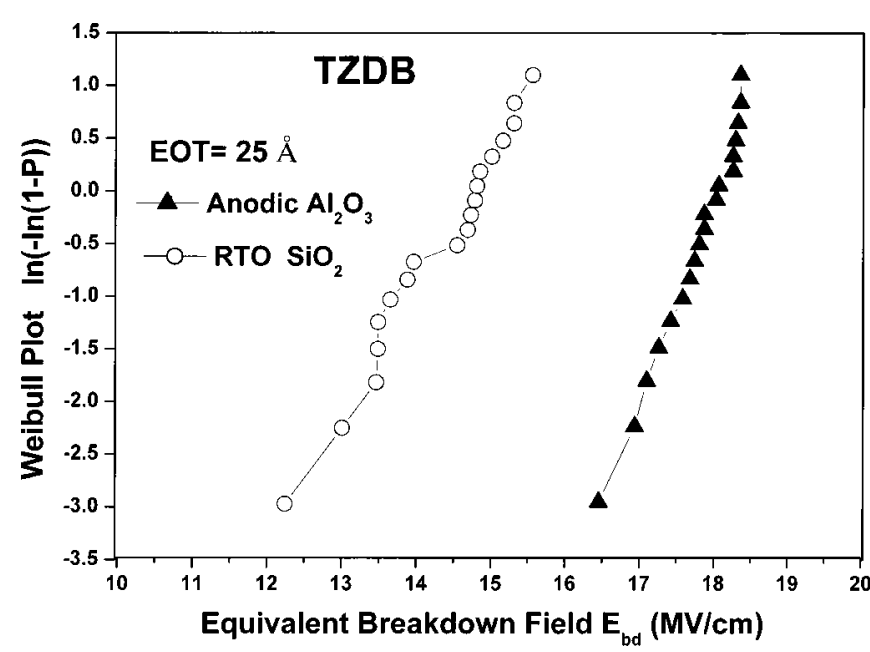

Figure 11. Weibull plot of TZDB characteristic for anodic $\mathrm{Al}_{2} \mathrm{O}_{3}$ and $\mathrm{SiO}_{2}$ samples with an EOT of $25 \AA$. 


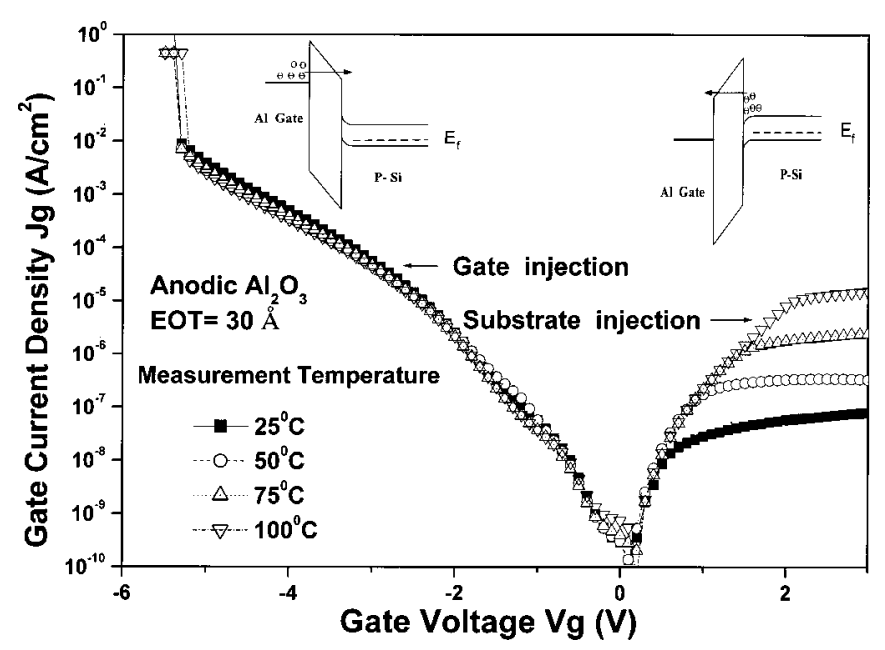

Figure 12. $\mathrm{J}-\mathrm{V}$ plots of anodic $\mathrm{Al}_{2} \mathrm{O}_{3}$ samples measured at various temperatures from 25 to $100^{\circ} \mathrm{C}$.

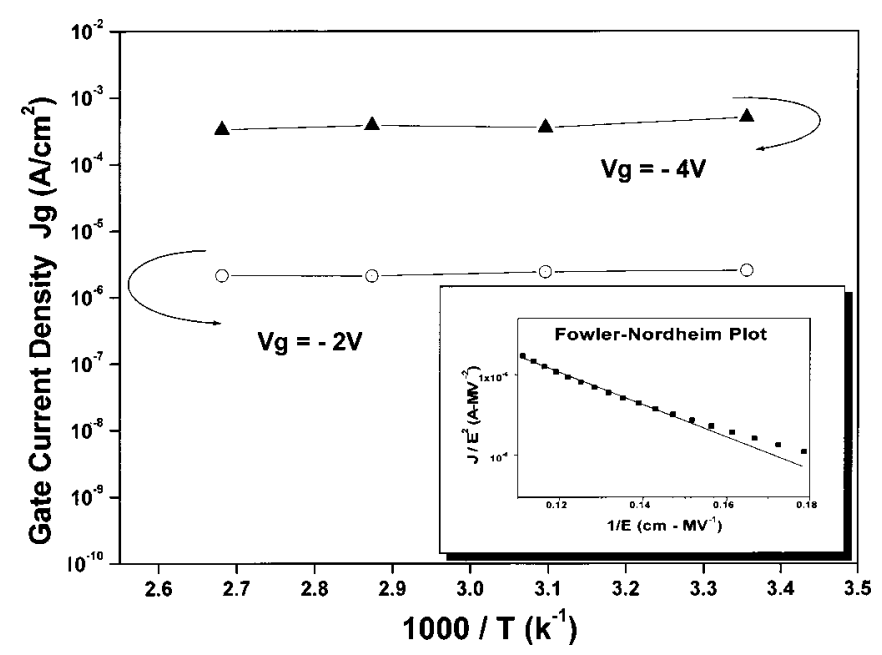

Figure 13. Gate current density $J \mathrm{~g}$ vs. inverse of temperature for an $\mathrm{Al}_{2} \mathrm{O}_{3}$ sample biased at -2 and $-4 \mathrm{~V}$. The F-N plot of this sample is also shown in the inserted figure. acteristics. It was supposed that the self-readjustment nature of leakage path under electric field accounts for the good insulator characteristics of anodic $\mathrm{Al}_{2} \mathrm{O}_{3}$. The proposed technique is simple and cost effective. Also, the observed high- $k$ characteristics of anodic $\mathrm{Al}_{2} \mathrm{O}_{3}$ are apparent for gate dielectric application. We think it is possible to use this technique to prepare other high- $k$ materials in the near future.

\section{Acknowledgments}

The authors want to thank the NTHU Instrument Center for supporting ESCA and AES analyses and the National Science Council of Republic of China for supporting this work under contract no. NSC-91-2215-E002-002.

National Taiwan University assisted in meeting the publication costs of this article.

\section{References}

1. B. Yu, H. Wang, C. Riccobene, Q. Xiang, and M. R. Lin, Technical Digest for VLSI Symposium, p. 90 (2000)

2. J. Kolodzey, E. A. Chowdhury, T. N. Adam, G. Qui, I. Rau, J. O. Olowolafe, J. S. Suehle, and Y. Chen, IEEE Trans. Electron Devices, 47, 121 (2000).

3. B. Y. Kim, H. F. Luan, and D. L. Kwong, Tech. Dig. Int. Electron Devices Meet., 1997, 463.

4. A. Kawamoto, J. Jameson, P. Griffin, K. Cho, and R. Dutton, IEEE Electron Device Lett., 22, 14 (2001).

5. S. Guha, E. Cartier, N. A. Bojarczuk, L. Gignac, and J. Karasinski, J. Appl. Phys. 90, $512(2001)$.

6. J. H. Lee, K. Koh, N. I. Lee, M. H. Cho, Y. K. Ki, J. S. Jeon, K. H. Cho, H. S. Shin, M. H. Kim, K. Fujihara, H. K. Kang, and J. T. Moon, Tech. Dig. Int. Electron Devices Meet., 2000, 645.

7. L. Manchanda, W. H. Lee, J. E. Bower, F. H. Baumann, W. L. Brown, C. J. Case, R. C. Keller, Y. O. Kim, E. J. Laskowski, M. D. Morris, R. L. Opila, P. J. Silverman, T. W. Sorsch, and G. R. Weber, Tech. Dig. Int. Electron Devices Meet., 1998, 605 .

8. M. Copel, E. Cartier, E. P. Gusev, S. Guha, N. Bojarczuk, and M. Poppeller, Appl. Phys. Lett., 78, 2670 (2001).

9. Y.-C. Chen, C.-Y. Lee, and J.-G. Hwu, Solid-State Electron., 45, 1531 (2001)

10. J. S. Liu, M. C. Chiang, C. L. Chen, and T. Y. Huang, in Proceedings of the 7th International Symposium on the Physical and Failure Analysis of Integrated Circuits, IEEE, p. 34 (1999).

11. K. J. Yang and C. Hu, IEEE Trans. Electron Devices, 46, 1500 (1999).

12. K. Yang, Y.-C. King, and C. Hu, Technical Digest for VLSI Symposium, p. 77 (1999).

13. M. Kundu, N. Miyata, and M. Ichikawa, Appl. Phys. Lett., 78, 1517 (2001).

14. F. J. Himpsel, F. R. Mcfeely, A. Taleb-Ibrahimi, and J. A. Yarmoff, Phys. Rev. B, 38, 6084 (1988).

15. E. H. Nicollian and J. R. Brews, MOS (Metal Oxide Semiconductor) Physics and Technology, Wiley \& Sons, New York (1982).

16. V. V. Afanas'ev and A. Stesmans, Phys. Rev. Lett., 80, 5176 (1998).

17. M. Bhat, G. W. Yoon, J. Kim, and D. L. Kwong, Appl. Phys. Lett. 64, 2116 (1994).

18. M. Y. Doghish and F. D. Ho, IEEE Trans. Electron Devices, 39, 2771 (1992).

19. Y. H. Shih and J. G. Hwu, IEEE Electron Device Lett., 22, 299 (2000).

20. M. Houssa, M. Tuominen, V. Afans'ev, A. Stesmans, S. Haukka, and M. M. Heyns, J. Appl. Phys., 87, 8615 (2000) 